Rodolfo Furlan Damiano (D)ttps://orcid.org/0000-0003-3180-7926

Hermano Tavares ${ }^{1}$

Ohttps://orid.org/0000-0002-6632-2745

\title{
COVID-19 highlights negligence with psychiatry patients in Brazilian general hospitals: a call for action
}

\author{
COVID-19 evidencia a negligência com pacientes psiquiátricos em \\ hospitais gerais brasileiros: uma chamada para a ação
}

DOI: $10.1590 / 0047-2085000000300$

\section{DEAR EDITOR,}

It is well known that due to multiple factors, psychiatric patients experience almost a decade of delay until intervention (DUI) to initiate a mental health treatment'. Moreover, some authors have already pointed out to a marked increase in mortality rate in individuals with mental disorders, highlighting a worse and delayed quality of healthcare for psychiatric patients with non-psychiatric illnesses ${ }^{2}$. Considering the fact that acutely mentally ill patients can be challenging, especially for untrained health staff, alongside with all the psychological and environmental stress precipitated by the COVID-19 pandemic, psychiatric patients are currently under even higher risk of medical negligence and larger DUI.

In order to overcome such a bleak state of affairs, we propose a combined intervention on three levels. First, there is the education of health professionals to-be. A recent multicenter controlled study ${ }^{3}$ proposed an antistigma intervention curriculum (ASIC), where medical students were submitted to clinical encounters with people living with serious mental illnesses followed by supervised small group discussions. Authors found that ASIC was effective in reducing stigma and also in changing attitudes toward psychiatry as a career choice.

Second, regarding treatment delivery, programs such as ASIC should be made available to professionals working at any health service potentially involved in the care of psychiatric patients. Besides, it is imperative that before overburdening the health staff with further responsibilities (courses, training, extra work hours, etc.), that health administrators take a time to remember usually forgotten practices that promote stress buffering and facilitates the emotional ventilation amongst professionals, in order to create a safe and healthy working environment.

Last, but not least, there is a well-known juxtaposition between psychiatric symptoms precipitated by stress and symptoms from general medical conditions, such as tremors, tachycardia, sweating, shortness of breath, and fatigue. However, such symptoms are not all equally modulated by the mental status ${ }^{4}$. For instance, chronic fatigue is known for having a low placebo response $\mathrm{e}^{5}$ and could be a more reliable indicator of respiratory compromise than self-reported dyspnea in pre-acute pulmonary failure. Considering the paucity of evidence in that regard, we acknowledge that such statement is highly speculative, but that should not stop us from inquiring into the merits of identifying red flags that may help health care providers discriminating psychiatric symptoms from symptoms indicating the need for urgent clinical intervention. In fact, it should be an incentive for fostering more research initiatives in the realm of liaison psychiatry services. This knowledge might promote better quality of care, reducing the DUI of psychiatric patients and consequently reduce their high mortality. 
Thus, COVID-19 pandemic evidence the worse quality of care that people living with severe mental illnesses might suffer in our general hospitals. Therefore, it is time to change teaching, clinical and research settings in order to promote the best quality of care to patients with psychiatric illnesses. Treating the most vulnerable individuals of our society, especially those with severe mental diseases is urgent and addressing this issue will help not only patients with mental illnesses but all the community.

\section{INDIVIDUAL CONTRIBUTIONS}

Rodolfo Furlan Damiano - Contributed with the design, writing and review.

Hermano Tavares - Contributed with the design, writing and review.

\section{CONFLICT OF INTERESTS}

Authors declare having no conflict of interests.

\section{REFERENCES}

1. Wang PS, Berglund PA, Olfson M, Kessler RC. Delays in initial treatment contact after first onset of a mental disorder. Health Serv Res. 2004;39(2):393-415.

2. Björkenstam E, Ljung R, Burström B, Mittendorfer-Rutz E, Hallqvist J, Weitoft GR. Quality of medical care and excess mortality in psychiatric patients - a nationwide register-based study in Sweden. BMJ Open. 2012;2(1):e000778.

3. Amsalem D, Gothelf D, Dorman A, Goren Y, Tene O, Shelef A, et al. Reducing Stigma Toward Psychiatry Among Medical Students: A Multicenter Controlled Trial. Prim Care Companion CNS Disord. 2020;22(2).

4. Wolters F, Peerdeman KJ, Evers AWM. Placebo and Nocebo Effects Across Symptoms: From Pain to Fatigue, Dyspnea, Nausea, and Itch. Front Psychiatry. 2019;10:470.

5. Cho HJ, Hotopf M, Wessely $\mathrm{S}$. The placebo response in the treatment of chronic fatigue syndrome: a systematic review and meta-analysis. Psychosom Med. 2005;67(2):301-13. 